\title{
Análise não linear e dimensionamento de torres metálicas de telecomunicação submetidas aos efeitos do vento conforme a NBR6123
}

\section{Mateus Marchi Lins (IC)}

\section{Resumo}

Este projeto de iniciação científica tem como objetivo a análise mais criteriosa dos esforços de vento atuantes em torres de telecomunicação, que impactam em seu dimensionamento. Visa-se a comparação dos esforços atuantes na torre, obtidos pelos diferentes métodos de cálculo propostos pela NBR6123/1998.

Palavras Chave: Torres de telecomunicação, Ações estáticas do vento, Ações dinâmicas do vento

\section{Introdução}

Compara-se os esforços atuantes em uma torre autoportante treliçada de $100 \mathrm{~m}$ de altura, de base triangular, composta por perfis cantoneira simples, pelos métodos Estático, Dinâmico Simplificado e Dinâmico Discreto, segundo as recomendações da NBR6123/1998.

\section{Resultados e Discussão}

Após a revisão bibliográfica necessária para 0 embasamento teórico do estudo, modela-se a torre de telecomunicação no software de desenho assistido por computador AutoCAD. Em seguida, exporta-se o desenho para o software de análise por método dos elementos finitos SAP2000, onde o modelo recebe suas propriedades geométricas, condições de vínculo e restrições.

Calcula-se os esforços atuantes de vento segundo a NBR6123/1998, pelos métodos Estático, Dinâmico Simplificado e Dinâmico Discreto. Para a análise discreta, foi necessária uma prévia análise modal de modo a determinar as frequências de vibração da estrutura. Para o propósito desta pesquisa, limita-se o estudo aos três primeiros modos de vibração da torre.

Tabela 1. Análise modal da estrutura

\begin{tabular}{|l|l|}
\hline Frequência $1^{\circ}$ modo $(\mathrm{Hz})$ & 0,833 \\
\hline Frequência $2^{\circ}$ modo $(\mathrm{Hz})$ & 0,840 \\
\hline Frequência $3^{\circ}$ modo $(\mathrm{Hz})$ & 2,127 \\
\hline
\end{tabular}

Em posse dos resultados de forças de arrasto, o vento é aplicado no modelo computacional da torre, decomposto e aplicado nos nós dos montantes, nas alturas em que se calculou 0 vento. Obtém-se assim os esforços resultantes na torre de telecomunicação, para os ventos atuantes nas direções de $0^{\circ}, 30^{\circ}$ e $60^{\circ}$ em relação à perpendicular à face da torre.

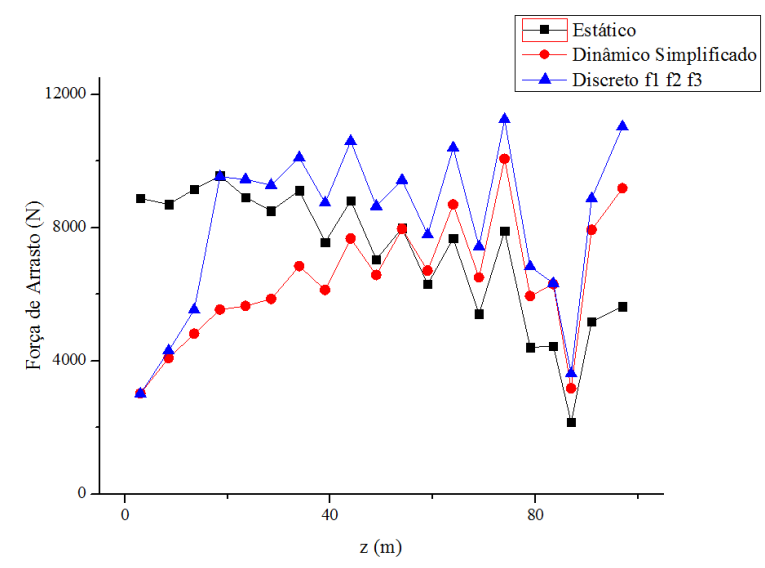

Figura 1. Forças de arrasto atuantes.

\section{Conclusões}

Observa-se a importância da consideração dos efeitos dinâmicos do vento no dimensionamento de torres de telecomunicação. O método estático oferece resultados aceitáveis a alturas abaixo de $50 \mathrm{~m}$, mas diverge demasiadamente dos resultados propostos pelas análises dinâmica simplificada e dinâmica discreta para maiores alturas. A análise dinâmica discreta, apesar de exigir maior esforço de cálculo, resulta em um dimensionamento mais criterioso e confiável.

\section{Agradecimentos}

Agradeço ao Prof. Dr. Cilmar Donizeti Baságlia, orientador deste projeto, pelo incentivo, confiança e dedicação de seu tempo neste projeto. Agradeço à minha família, amigos e namorada, pelo carinho, apoio e zelo.

NASCIMENTO, Fernanda O. D. A. Análise de estruturas metálicas de torres treliçadas autoportantes para telecomunicações. 2002. 146 f. Dissertação de Mestrado, Universidade Estadual de Campinas, Campinas, 2002.

Associação Brasileira de Normas Técnicas (ABNT), NBR-6123: Forças Devidas ao Vento em Edificações, Rio de Janeiro, 1998. 